Check for updates

The BMJ

Cite this as: $B M J 2021 ; 372: n 728$ http://dx.doi.org/10.1136/bmi.n728 Published: 16 March 2021

\title{
Covid-19: WHO says rollout of AstraZeneca vaccine should continue, as Europe divides over safety
}

\section{Elisabeth Mahase}

Doctors have warned of the risks associated with pausing or delaying vaccination programmes against covid-19, as the number of European countries that have halted use of the Oxford University and AstraZeneca vaccine rose to 16 .

Denmark, Norway, Bulgaria, Iceland, France, Germany, Italy, Spain, Portugal, Slovenia, and Cyprus have suspended all use of the vaccine. ${ }^{1}$ Five other countries (Austria, Estonia, Latvia, Lithuania, and Luxembourg) have paused the use of a single batch of a million doses of the vaccine.

The moves came after reports of blood clotting disorders in some countries. The Norwegian Medicines Agency said last week that it was looking into several cases of blood clots or reduced platelet counts, including at least one death from a brain haemorrhage. Danish authorities also launched a safety review into the vaccine after the death of one recipient, while Austrian officials said that one person who had multiple thrombosis diagnosed after vaccination from a specific batch had died and that another was recovering from pulmonary embolism.

The World Health Organization and the European Medicines Agency have said that there does not seem to be an increased risk of blood clots with the vaccine and have advised that vaccinations should continue. On 16 March WHO's chief scientist, Soumya Swaminathan, said, "We do not want people to panic, and we would, for the time being, recommend that countries continue vaccinating with AstraZeneca . . .So far, we do not find an association between these events and the vaccine."

The EMA said there had been 30 reports of thromboembolic events among nearly five million people given the AstraZeneca vaccine in the European Economic Area. ${ }^{2}$

AstraZeneca has said 37 blood clots have been reported out of more than 17 million people vaccinated in the EU and Britain. Five of the cases were deep vein thrombosis, and 22 were pulmonary embolisms. "This is much lower than would be expected to occur naturally in a general population of this size and is similar across other licensed covid-19 vaccines," it said in a statement.

Phil Bryan, vaccines safety lead at the UK Medicines and Healthcare Products Regulatory Agency, said, "Blood clots can occur naturally and are not uncommon. More than 11 million doses of the AstraZeneca vaccine have now been administered across the UK, and the number of blood clots reported after having the vaccine is not greater than the number that would have occurred naturally in the vaccinated population.
"We are working closely with international counterparts in understanding the global safety experience of covid-19 vaccines and on the rapid sharing of safety data and reports. People should still go and get their covid-19 vaccine when asked to do so."

Belgium, Poland, Ukraine, and the Czech Republic have followed advice from the UK's regulators to keep vaccinations going.

WHO's Advisory Committee on Vaccine Safety and the EMA were both due to meet to review the available data on 16 March, as The BMJ went to press.

Stephen Griffin, associate professor in the School of Medicine at the University of Leeds, said that, although reports of a small number of blood clots should be investigated, the response of many countries to halt vaccinations was disproportionate. "Since many European countries are currently experiencing another resurgence of SARS-CoV-2 infections and yet are lagging behind in terms of rollout, the importance of continuing the vaccination programmes cannot be overestimated, and the harm caused by depriving people of access to a vaccine will likely vastly outweigh even the worst case scenario if any link to the clotting disorders is eventually found. It should also be noted that nationwide gestures such as this are bound to fuel hesitancy, or more extreme antivaccine sentiment, further undermining the vaccination effort," he said.

Paul Hunter, professor in medicine at the University of East Anglia, said, "The infection mortality rate in men in their mid-40s from covid-19 is of the order $0.1 \%$ or about 1000 deaths per million infections, substantially greater than the risk of CVT [cerebral venous thrombosis]. Clearly, this possible association needs to be thoroughly investigated, but we do need to consider the real harm from delays in immunisation campaigns at a time when the incidence of covid-19 is still increasing in several European countries, when deciding whether or not to pause vaccination campaigns."

There has been no evidence of serious adverse effects from clinical trials of the AstraZeneca vaccine. ${ }^{3}$

\section{Correction: The number of European countries that have halted use of the Oxford University and AstraZeneca vaccine was 16, not 17. The first paragraph has been corrected.}

Wise J. Covid-19: European countries suspend use of Oxford-AstraZeneca vaccine after reports of blood clots. BMJ2021;372:n699. doi: 10.1136/bmj.n699 pmid: 33707182

2 European Medicines Agency. Covid-19 vaccine AstraZeneca: PRAC investigating cases of thromboembolic events-vaccine's benefits currently still outweigh risks: update. Mar 2021. https://www.ema.eu-

ropa.eu/en/news/covid-19-vaccine-astrazeneca-prac-investigating-casesthromboembolic-events-vaccines-benefits. 
3 Voysey M, Clemens SAC, Madhi SA, etalOxford COVID Vaccine Trial Group. Safety and efficacy of the ChAdOx1 $\mathrm{nCoV}$-19 vaccine (AZD1222) against SARS-CoV-2: an interim analysis of four randomised controlled trials in Brazil, South Africa, and the UK. Lancet 2021;397:99-111. doi: 10.1016/S0140-6736(20)32661-1 pmid: 33306989

This article is made freely available for use in accordance with BMJ's website terms and conditions for the duration of the covid-19 pandemic or until otherwise determined by BMJ. You may use, download and print the article for any lawful, non-commercial purpose (including text and data mining) provided that all copyright notices and trade marks are retained. 